\title{
O DITO ENIGMÁTICO "EN TOÎS TOÛ PATRÓS MOU” (LC 2,49C): UMA PROPOSTA DE TRADUÇÃO *
}

The enigmatic saying "en toîs toû patrós mou" (Lk 2:49c): a proposal for translation

Márcia Eloi Rodrigues **

RESUMO: Este estudo visa contribuir com a discussão acerca da interpretação do dito enigmático "en tô̂s toû patrós mou"1 (Lc 2,49c) no episódio de Jesus aos doze anos (Lc 2,41-52), mostrando a importância de se ater ao sentido original do texto grego para se obter uma melhor compreensão da intenção comunicativa desse relato. A exposição contempla os principais estudiosos modernos do Evangelho lucano, com indicações de importantes traduções das Bíblias em diversas línguas, e uma breve análise das palavras oîkos e oikía, que correspondem aos vocábulos "casa", "habitação", "família" etc. em português, e seu emprego como metáfora da "casa do Pai" (Templo), a fim de descartar essa tradução em favor de outra, mais aberta, a saber: "nas coisas do meu Pai". Com isso, se pretende fundamentar a hipótese de que Lucas pretendeu escrever um texto ambivalente como estratégia narrativa e comunicativa, em virtude da cooperação do leitor na atualização do texto evangélico. Dessa forma, a narrativa permaneceria com um final "aberto" a ser preenchido pelo leitor ao longo de sua leitura do Evangelho lucano.

PALAVRAS-CHAVE: Ambivalência. Casa. Coisas. Narrativa da infância. Interpretação.

\footnotetext{
* O artigo é uma adaptação da tese doutoral "“En tois tou patros mou' (Lc 2,49): a identidade messiânica de Jesus segundo Lc 2,41-52 (e Lc 4,16-30)", tópicos 1.2 e 1.3 do primeiro capítulo (Problema e estado da questão, p. 26-39), defendida junto à Faculdade Jesuíta de Filosofia e Teologia - FAJE / 2019 e orientada pelo prof. Dr. Johan Konings com o apoio da CAPES - PROEX. A tese está disponível em: <https://www.faculdadejesuita.edu.br/teses-teologia-227/-en-tois-tou-patros-mou-lc-2-49-a-identidade-messianica-de-jesus-segundo-lc-2-41-52-e-lc-4-16-30--24062020-151120>.

* Seminário Provincial Sagrado Coração de Jesus, Diamantina, Minas Gerais, Brasil.

${ }^{1}$ Para a transliteração dos caracteres grego, adotamos o uso frequente dos autores bíblicos citados no presente artigo, com a inclusão da acentuação.
} 
ABSTRACT: This study aims to contribute to the discussion about the interpretation of the enigmatic saying "en tô̂s tôu patrós mou" (Lk 2:49c) in the episode of Jesus at twelve years old (Lk 2:41-52), showing the importance of observing the original meaning of the Greek text, to gain a better understanding of the communicative intent of the gospel text. The exposition includes leading modern scholars of the Lucan Gospel, with indications of important Bible translations in various languages, and a brief analysis of the words oîkos and oikia, which correspond to the words "house", "habitation", "family" etc. in English, and its use as a metaphor for the "Father's house" (Temple), in order to discard this translation in favor of another, more open one, namely: "in my Father's things". So, we support the hypothesis that Luke intended to write an ambivalent text as a narrative and communicative strategy, due to the reader's cooperation in updating the gospel text. In this way, the narrative would remain with an "open" ending to be filled by the reader throughout his reading of the Lucan Gospel.

KEYWORDS: Ambivalence. House. Things. Infancy Narrative. Interpretation.

\section{Introdução}

Sagrada Escritura é o livro mais traduzido no mundo inteiro e, particu-
larmente no Brasil, se percebe uma crescente diversificação de traduções. Esse fenômeno é bem antigo! A razão de tal multiplicação de traduções "é que nenhuma tradução consegue transpor (trans-duzir) perfeitamente, com todas as suas nuances e conotações, o sentido primeiro do texto" (KONINGS, 2014 , p. 22, grifo do autor). Os vários tipos de traduções pretendem uma maior aproximação ao sentido original veiculado pelo texto sagrado e, ao mesmo tempo, oferecer traduções para os diversos tipos de usos e leitores (KONINGS, 2014, p. 22). Assim, toda e qualquer leitura ou estudo do texto bíblico deverá, sem o conhecimento da língua original, apoiar-se em uma boa tradução da Bíblia, a fim de se compreender a mensagem veiculada pelo texto sagrado. Esse é nosso objetivo no presente estudo!

O trecho escolhido, a saber: "en tô̂s toû patrós mou" (Lc 2,49c) ${ }^{2}$, diz respeito ao dito enigmático tirado da perícope de Jesus aos doze anos (Lc $2,41-52$ ), texto que conclui a narrativa da infância (Lc 1,5-2,52). A escolha desse texto consiste em sua importância cristológica, uma vez que encerra o processo de revelação da identidade messiânica de Jesus na narrativa da infância e apresenta chave de leitura para todo o evangelho lucano. Nesse episódio, Jesus é encontrado no Templo, onde fala pela primeira vez, proferindo um dito enigmático (Lc 2,49c) de suma importância para a compreensão da mensagem do episódio. Em vista disso, fica patente a

\footnotetext{
${ }^{2}$ A segmentação de Lc 2,49 foi realizada segundo os elementos sintáticos: a. kaì eîpen pròs autoús:; b. tí hóti ezēteîté me?; c. ouk êdeite hóti en tô̂s toû patrós mou dê̂ eînai me?.
} 
necessidade de esclarecer o sentido desse dito misterioso que constitui, segundo muitos autores, a via crucis da exegese de Lc 2,41-52.

Nosso estudo partirá da exposição dos diversos autores modernos a respeito da interpretação ${ }^{3}$ do trecho en toîs tô̂ patrós mou, seguida de uma breve análise dos vocábulos oîkos e oikía em Lc-At, usados com o significado "casa", "habitação", "família" etc. Por fim, proporá uma tradução do sintagma em questão e sua ambivalência como importante procedimento retórico lucano.

\section{A interpretação de en toîs toû patrós mou segundo os autores modernos}

A interpretação da frase ouk édeite hóti en toîs tôิ patrós mou dề einaí me (Lc 2,49c), que significa literalmente "Não sabíeis que em as (coisas) do Pai meu é necessário estar eu?"4, é pauta de uma longa discussão entre os estudiosos do relato lucano da infância ${ }^{5}$. A questão centra-se sobre qual seria o substantivo específico substituído pelo artigo neutro plural toîs ${ }^{6}$, precedido pela preposição en. As traduções são diversas, todas elas baseadas em análises sintática e contextual, em ocorrências em textos bíblicos e patrísticos, que podem ser verificadas nas bibliografias dedicadas a essa questão. Dentre elas, podemos destacar a obra de Laurentin, Jésus au Temple (1966, p. 38-72), que apresenta uma análise extensa dos termos en tô̂s no dito de Jesus e várias possibilidades de interpretação, a saber: coisas, pessoas, domínio, negócios, casa ou habitação.

Laurentin, em seu estudo, reúne uma lista considerável de testemunhas, desde a patrística grega e latina até os autores modernos de sua época, possibilitando-nos vislumbrar mais ou menos 18 séculos de interpretação

\footnotetext{
${ }^{3}$ A terminologia "interpretação" ao invés de "tradução" corresponde à linguagem empregada pelos estudiosos, que consideram do ponto de vista interpretativo, uma vez que, segundo eles, há a ausência de um substantivo.

${ }^{4}$ Tradução literal segundo BÍBLIA. Novo Testamento interlinear grego-português. Barueri, SP: Sociedade Bíblica do Brasil, 2004. Não há, segundo NESTLE-ALAND. Novum Testamento Graece. 2.Aufl. Stuttgart: Deutsche Bibelgesellschaft, 2012, questões de crítica textual referente a Lc 2,49. O debate dos autores consiste no acréscimo de um substantivo que interprete o sentido da locução en toîs.

${ }^{5}$ Em geral, os autores que se dedicam ao estudo do Evangelho segundo Lucas (F. Bovon, J. Fitzmyer, J. Schmid, R. J. Karris etc.) também se atêm à questão da interpretação do en tô̂s. No entanto, menciono aqui, de modo particular, os estudiosos do relato da infância ( $R$. Laurentin, R. E. Brown, A. Valentini, G. Ferraro etc.) porque a pesquisa do presente artigo está delimitada à narrativa da infância segundo Lucas.

${ }^{6} \mathrm{O}$ artigo definido tô̂s pode ser o dativo plural do artigo masculino (ho) ou neutro (tó), pois ambos são grafados da mesma forma (SWETNAM, 2004, p. 18 e 42). No entanto, a interpretação mais óbvia para o tô̂s seria o dativo neutro plural (FITZMYER, 1987, t. II, p. 286).
} 
da cláusula en toîs tô̂ patrós mou. Por esse motivo, delimitamos esse autor como ponto de partida da exposição do assunto em questão.

Embora Laurentin apresente cinco possibilidades de tradução dos termos en tô̂s, nem todos eles serão apresentados neste artigo por dois motivos. Primeiramente, o estudo do referido autor já contribuiu com uma análise bem extensa das possibilidades de interpretação do en tô̂s, que poderá ser conferida por quem o desejar. Nossa intenção é apresentar apenas a escolha de interpretação de autores que dialogam com ele. Em segundo lugar, alguns desses substantivos são tratados por muitos autores como similares, o que reduz esse número a três possibilidades, correspondentes aos sentidos local, funcional e pessoal (BROWN, 1993, p. 475-477) ${ }^{7}$.

No entanto, segundo Brown (1993, p. 693-694), a tradução em sentido pessoal ("entre os parentes") tem poucos adeptos ${ }^{8}$, e as duas possibilidades mais recorrentes entre os estudiosos situam-se nos sentidos local e funcional ${ }^{9}$. Assim, organizamos a exposição do assunto a partir desses dois últimos sentidos, elencando os estudiosos que defendem um ou outro, como possibilidade de interpretação dos termos en toîs:

A primeira possibilidade confere um sentido local ao sintagma en tôิs tôิ patrós mou, interpretando-o por "na casa de meu Pai", em referência indireta ao Templo ${ }^{10}$. Esta interpretação conta com maior respaldo na Escritura e é considerada por muitos autores ${ }^{11}$ a tradução mais óbvia, devido ao local onde Jesus é encontrado (WEINERT, 1983, p. 19).

A segunda consiste em interpretar o sintagma em sentido funcional: "em/a respeito das coisas/dos negócios/dos assuntos de meu Pai". Essa interpretação ganhou notoriedade nas últimas décadas e adquire cada vez mais adeptos entre os pesquisadores, por assegurar uma interpretação mais "aberta" do dito enigmático de Jesus (BROWN, 1993, p. 693).

\footnotetext{
7 Segundo Laurentin (1966, p. 46-47), a interpretação "no domínio" ou "na esfera de Deus" é apenas uma variação do tema "na casa do meu Pai", inspirada pela preocupação de ultrapassar a materialidade do símbolo, considerado pueril ou trivial por alguns autores modernos. Facilmente se pode passar do domus à domaine, da habitação onde reside o mestre da casa (dominus) a tudo o que se encontra sob seu dominium.

${ }^{8}$ Os autores que consideram "tôิs" como artigo masculino interpretam o sentido pessoal

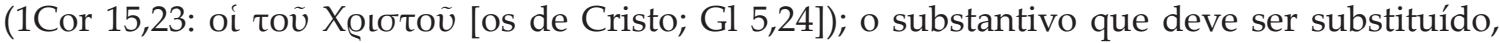
nesses casos, geralmente significa uma relação de parentesco próximo (cf. filho [Mt 10,2:

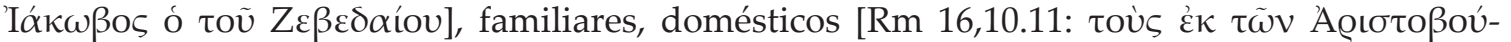
$\lambda$ ov, os dentre os de Aristóbulo; Rm 16,11]). Nesse caso, precisaria compreender em Lc 2,49, "entre os familiares de meu Pai", "aqueles que habitam sua casa", no caso, os doutores da lei. Mas esta concepção seria pouco conforme à perspectiva lucana considerar os escribas e fariseus a verdadeira família de Jesus (cf. LAURENTIN, 1966, p. 42-43).

${ }^{9}$ Cf. também WEINERT, 1983, p. 19-20; DE JONGE, 1978, p. 331.

${ }^{10}$ As referências bibliográficas serão apresentadas ao longo da discussão.

${ }^{11}$ Laurentin (1966, p. 64) elenca em nota de rodapé esses autores e suas respectivas obras; limito-me a apresentar alguns dos autores abordados mais à frente na discussão, a saber: Laurentin, Brown e Rodríguez Carmona.
} 


\subsection{Sentido local (casa/templo)}

Conforme vimos acima, Laurentin dedica extensa análise aos termos en tô̂s, reunindo várias propostas de interpretação com uma ampla referência bibliográfica. Ele analisa cada uma das propostas, mas, contrariamente à disciplina científica, deixa clara, já no início, a sua interpretação: "de todos esses sentidos, apenas um é admissível, o último: "na casa de meu Pai'" (LAURENTIN, 1966, p. 39, tradução nossa). Por conseguinte, ele rejeita categoricamente qualquer outra tradução que não seja "casa de meu Pai", como referência indireta ao "Templo" (LAURENTIN, 1966, p. 72) ${ }^{12}$. Sua posição é muito criticada pelos autores que reconhecem a possibilidade de mais de uma interpretação para o en toîs.

Brown (1993, p. 471) também adota a interpretação "na casa de meu Pai" para o sintagma en toîs tô̂ patrós $m o u^{13}$. E, em seu comentário ao texto de Lc 2,49, enfatiza que o sentido é indireto, pois Lucas não emprega aqui o vocábulo "oîkos" (BROWN, 1993, p. 490). Segundo Brown (1993, p. 476), o contexto narrativo em que os pais de Jesus procuram por ele, bem como o local no qual ele foi encontrado, substitui apropriadamente um substantivo de local.

Nessa mesma linha, Brown apoia a interpretação do sintagma com o sentido de "na morada (casa) de meu Pai", atestada em alguns textos da Septuaginta (LXX) (cf. Jó 18,19; Est 7,9). Fator importante a favor da interpretação "casa" é que Lucas emprega em algumas ocasiões a expressão "casa de Deus", em referência ao templo de Jerusalém (cf. Lc 6,4; 19,46); e tem o apoio das versões siríaca, armênia e persa, dos Padres da Igreja gregos e de muitos dos Padres latinos que seguiram Agostinho de Hipona (BROWN, 1993, p. 476).

Novos estudos a respeito de Lc 2,49 são apresentados por Brown (1993, p. 571-712) em um "Suplemento" acrescentado a sua nova edição do "The Birth...", que reúne as últimas pesquisas acerca dos Evangelhos da Infância a partir do diálogo com a literatura escrita de 1976 a 1992. Ele reafirma sua escolha pela interpretação "na casa de meu Pai", mas menciona a tendência atual de evitar atribuir sentido exclusivo à frase. Segue expondo alguns autores, como F. D. Weinert, J. Kilgallen e D. D. Sylva, que propõem uma interpretação "múltipla", que contemple os significados local, funcional e pessoal (BROWN, 1993, p. 693). Brown rejeita a interpretação - defendida por Kilgallen e Sylva - que propõe significado dual, casa e assuntos,

\footnotetext{
${ }_{12}$ Para Laurentin (1966, p. 72), a expressão francesa "chez" traduz melhor o final de Lc 2,49, em vez do vocábulo maison. Em nota, ressalta que o termo francês chez significa etimologicamente casa.

${ }^{13}$ Nas pp. 475-477, Brown apresenta uma síntese das principais interpretações dessa expressão de construção tão ambígua.
} 
ambos relacionados à atividade de Jesus de ensinar, que teria o objetivo de antecipar sua atividade futura de ensino do Templo (Lc 19,47; 21,37). Ele duvida que a expressão signifique algo tão preciso como "ensinar" (BROWN, 1993, p. 693-694). A partir dessa hipótese, ele considera a melhor tradução, além de "na casa de meu Pai", o texto mais abrangente "a respeito dos assuntos de meu Pai", e cita De Jonge, que acredita que as palavras de Jesus abrangem não apenas a casa do Pai, mas dizem respeito ao plano divino (BROWN, 1993, p. 694).

Fitzmyer (1987, p. 286) afirma que não é fácil definir com exatidão o significado preciso da expressão en toîs toû patrós mou no contexto em que o dito é proferido. Ele assegura que a locução grega pode ser traduzida por "na casa de meu Pai", "nas coisas, nos assuntos de meu Pai", como também "entre os parentes que pertencem a meu Pai", se o artigo "toîs" for considerado não como neutro, segundo a interpretação mais óbvia, mas como masculino plural. No entanto, Fitzmyer (1987, p. 287) adota a interpretação "na casa de meu Pai", em referência indireta ao Templo, e apresenta como apoio para essa escolha os numerosos textos bíblicos e extrabíblicos nos quais essa construção en toîs, seguida de genitivo de pessoa, significa "a casa (a família) de N". Ele afirma, ainda, que esse sentido, "na casa...", seria mais natural nos lábios de um adolescente do que os outros, por serem mais abstratos.

Rodríguez Carmona (1992, p. 187) adota a tradução "eu esteja permanentemente na casa de meu Pai" e em nota apresenta as duas outras possibilidades, "nas coisas" e "entre os". Sua justificativa para a tradução "na casa" está no fato de que Jesus falou isso no Templo. Ele cita Schürmann, que afirma a importância do Templo neste episódio como lugar da instrução e que a interpretação explicita melhor o sentido da total dedicação de Jesus à palavra de Deus (apud RODRÍGUEZ CARMONA, 1992, p. 188).

Além dos autores aqui apresentados, as diversas Bíblias internacionais e suas traduções brasileiras, que adotaram a interpretação "na casa" para o en toîs, indicam que essa interpretação caiu no uso comum ${ }^{14}$. No entanto, uma interpretação unilateral dessa cláusula enigmática é considerada problemática por muitos autores. A questão é que o contexto narrativo de Lc 2,41-52 oferece pistas para uma interpretação ambígua do dito de Jesus no v. 49.

\footnotetext{
${ }^{14}$ As traduções americanas: New Revised Standard Version (NRS) (1637) e New Revised Standard Version (NRS) (1989), encontradas no software BibleWorks 8. As traduções brasileiras: Almeida Revista e Atualizada (ARA) (1993); A Bíblia de Jerusalém (2002); Bíblia Sagrada: Nova Versão Internacional (2000); Bíblia Sagrada Almeida Século 21: Antigo e Novo Testamento (2008); Bíblia Sagrada: Nova Tradução na Linguagem de Hoje (NTLH) (1989); A Bíblia do Peregrino (2011). Em sentido contrário, a neerlandesa Willibrord mudou a tradução de 1978 "na casa" para "junto de" (1995), o que demonstra que não há uma tendência clara de privilegiar a palavra "casa" para interpretar a expressão en toîs de Lc 2,49c.
} 
Antes, porém, de dar continuidade à exposição dos estudiosos acerca da tradução da locução en toîs, verificaremos brevemente o emprego dos vocábulos oîkos/oikía ${ }^{15}$ em Lucas-Atos, a fim de abrir caminho para uma interpretação mais aberta do referido sintagma.

\subsection{Análise do emprego dos vocábulos oîkos/oikía na obra lucana}

Segundo a análise de Robert Morgenthaler (1992, p. 124), das 94 vezes que o vocábulo oikía aparece no Novo Testamento, 25 são encontrados no Evangelho de Lucas e 12 no Atos dos Apóstolos ${ }^{16}$. E, das 112 ocorrências do vocábulo oîkos no Novo Testamento, 58 vezes estão na obra lucana (33 em Lucas; 25 em Atos) $)^{17}$. Analisaremos apenas as ocorrências em que esses vocábulos estão referidos ao Templo e à família.

\subsubsection{Os vocábulos oîkos/oikía relacionados ao Templo}

Em Lc 6,4, aparece pela primeira vez a palavra ô̂kos referida ao Templo ([hōs] eisềlthen eis tòn oîkon toû theô̂ [como entrou na casa de Deus]). Esse trecho encontra-se também em Mt 12,4 e Mc 2,26 e é uma referência ao relato de $1 \mathrm{Sm}$ 21,2-7. O texto de Samuel não contém o vocábulo oîkos, nem menciona o Templo, mas a narrativa refere-se aos pães da proposição que o sacerdote disponibiliza para Davi e seus homens no templo/santuário de Nob. Como o trecho encontra-se nos três sinóticos, provavelmente não é composição lucana, mas provém de uma fonte comum (Mc).

Em Lc 11,51, o vocábulo ô̂kos é referido ao Templo, numa alusão ao texto de 2Cr 24,20-22, em que é empregada no trecho a expressão en aulê̄ oíkou küríou (v. 21: no pátio da Casa do Senhor). Lucas conserva somente o termo oîkos no genitivo, subentendido como casa de Deus $(11,51:$ [...] toû apoloménou metaxù tôิ thüsiastēríou kaì tôิ oíkou [o que pereceu entre

\footnotetext{
15 "Originalmente, havia diferenciação entre as duas palavras quanto ao seu significado, sendo que oikia denotava o lugar da moradia, e oikos a 'casa' inteira, com as dependências, os bens da família, e até os habitantes da casa. [...] Mais tarde, particularmente depois da LXX, as distinções não se mantinham, e as palavras eram empregadas como sinônimos" (COENEN; BROWN, 2000, p. 285). Segundo LOUW; NIDA (2013, p. 74), ambos os vocábulos fazem parte do domínio semântico "construções". Oikía designa uma construção ou lugar onde alguém mora ("casa, lar, morada, residência"), enquanto oîkos designa uma construção com um ou mais compartimentos e que normalmente é usada como lugar de habitação ("casa, templo, santuário"). A extensão da lexia ô̂kos para incluir templos pode ser resultado do fato de se falar de um templo como habitação da divindade. Cf. tb. RUSCONI, 2003, p. 328-329.

${ }^{16}$ Lc 4,38; 5,29; 6,48.48.49.49; 7,6.37.44; 8,27.51; 9,4; 10,5.7.7.7.38; 15,8.25; 17,31; 18,29; 20,47; $22,10.11 .54$; At 4,$34 ; 9,11.17 ; 10,6.17 .32 ; 11,11 ; 12,12 ; 16,32 ; 17,5 ; 18,7.7$.

${ }^{17}$ Lc 1,23.27.33.40.56.69; 2,4; 5,24.25; 6,4; 7,10.36; 8,39.41; 9,61; 10,5.38; 11,17.24.51; 12,39.52; 13,35; $14,1.23 ; 15,6 ; 16,4.27 ; 18,14 ; 19,5.9 .46 .46$; At 2,2.36.46; 5,42; 7,10.20.42.46.47.49; 8,3; 10,2.22.30; $11,12.13 .14 ; 16,15.15 .31 .34 ; 18,8 ; 19,16 ; 20,20 ; 21,8$.
} 
o altar e a casa (de Deus)] $)^{18}$. Mt 23,35 substitui a palavra oîkos por naós, que se refere à parte mais interna do Templo, o santuário ${ }^{19}$.

Em Lc 13,34-35, Jesus chora sobre Jerusalém e profere um oráculo sobre o Templo, que é expresso pelo vocábulo oîkos (v. 35a: idoù aphíetai hümîn ho ô̂kos hümồn [Eis, vossa casa é abandonada a vós]). Aqui o trecho faz alusão a textos proféticos (Jr 7,14; 12,7; 26,6; Mq 3,12), nos quais são empregados o vocábulo ô̂kos para se referir ao Templo. Mt 23,38 reproduz o mesmo texto lucano.

Na narrativa da purificação do Templo (Lc 19,45-47), Lucas emprega a expressão ho oîkos mou em referência ao Templo (v. 46: kaì éstai ho oîkós mou oîkos proseuchê̄s [e a minha casa será casa de oração]), numa citação direta da última frase de Is 56,7 (ho gàr oîkós mou oîkos proseuchēs klêthsêtai pásin tô̂s éthnesin [pois a minha casa será chamada casa de oração para todos os povos]), com a supressão do sintagma "para todos os povos"20. Mt 21,13 emprega a mesma citação, como Lucas, enquanto Mc 11,17 cita Is 56,7 na íntegra.

Em Atos dos Apóstolos, há somente duas ocorrências do vocábulo oîkos relacionado ao Templo, no discurso de Estêvão aos judeus, em que faz uma releitura da história de Israel para convencer seus ouvintes que Jesus é o Messias (At 7,1-54). No final do discurso, há referência a 1Rs 6,1-2 em At 7,46-47 ([...] kaì êtếsato heureîn skếnōma tồ oíkō Iakốb. Solomòm dè oikodómēsen autồ oîkon: [...] e pediu para encontrar morada para a casa de Jacó. Mas Salomão construiu para ele uma casa), e uma citação de Is 66,1-2 em At 7,49 ([...] poîon oîkon oikodomèseté moi, légei kürios, ètís tópos tềs katapaúseós mou?: [...] que casa construireis para mim, diz o Senhor, ou que lugar do meu repouso?).

Quanto ao vocábulo oikía, relacionado ao Templo, não há nenhuma ocorrência em Lucas-Atos.

\subsubsection{Os vocábulos oîkos/oikía com sentido de "casa/família"}

Lucas emprega as lexias oîkos/oikía indistinta e sucessivamente, em uma mesma e única seção, com o significado de "casa", lugar onde alguém

\footnotetext{
18 "Tanto os Evangelhos como o livro dos Atos empregam em algumas passagens oîkos (inclusive sem o genitivo atributivo theô̂) com o significado de "casa (de De_us)" / templo. O termo, com este significado, se encontra unicamente em citações do AT (Mc 11,17a par. ["minha casa"]; 11,17b par. ["casa de oração"]; Jo 2,16 ["a casa de meu Pai"]; At 7,49) ou em alusões (Mc 2,26 par.; Lc 11,51; At 7,47) ou no contexto das mesmas (Jo 2,17 ["tua casa"]). Oikía não se acha atestada com esse significado" (WEIGANDT, 1998, p. 504).

${ }^{19}$ Naós significa, literalmente, morada; a morada de uma divindade, um templo; especificamente, a cela de um templo, daí o lugar santo do templo de Jerusalém (Mt 23,35; Lc 1,9) (MOUNCE, 2013, p. 424).

${ }^{20}$ Em comparação a Lc 2,49, somente em Jo 2,16-17 é que aparece a expressão "tòn ô̂kon tôิ patrós mou" (v. 16c), numa referência explícita ao Templo como "casa de meu Pai".
} 
mora (WEIGANDT, 1998, p. 501-502) ${ }^{21}$. Em Atos dos Apóstolos, os vocábulos oîkos/oikía são usados para designar o lugar da reunião de uma comunidade cristã (WEIGANDT, 1998, p. 503-504)22.

Quanto ao vocábulo oikía em Lucas-Atos, o significado é de "casa", nunca de "família". Já a palavra oîkos, Lucas a emprega com alternância de significado, ora "casa" (31 vezes) ou "família" (19 vezes). Em Lc 2,4, ôkkos é usado para designar parentesco: "dià tò eînai autòn ex oíkou kaì patriâs Dauíd" ("por ser ele da linhagem e descendência de Davi") (LOUW; NIDA, 2013, p. 105). É encontrado algumas vezes, na obra de Lucas, em uma mesma e única seção, o vocábulo oîkos com os significados alternativos de "casa" e "família": "hōs dè ebaptísthē kaì ho oîkos autềs, parekálesen légousa: ei kekríkaté me pistèn tô̄ küríō eînai, eiselthóntes eis tòn oîkón mou ménete: kaì parebiásato hēmâs." ("E quando foi batizada e a casa [família] dela, pediu dizendo: Se julgastes eu ser fiel ao Senhor, entrando na minha casa, ficai; e constrangeu a nós.") (At 16,15) ${ }^{23}$.

Esta breve análise nos possibilitou visualizar as diversas ocorrências, na obra lucana, em que os itens lexicográficos oîkos e oikía foram utilizados com sentido de templo e de família. Ao fim, podemos chegar a algumas conclusões:

- Em nenhum lugar o vocábulo oikía é usado para designar o Templo de Jerusalém.

- Há somente 7 ocorrências da palavra oîkos se referindo ao Templo (4 delas em Lucas e 3 em Atos dos Apóstolos) ${ }^{24}$. Em todas elas, o trecho corresponde a citações ou alusões a textos do Antigo Testamento.

- Lucas conhece bem as unidades lexicais oîkos (inclusive no sentido de "casa de Deus") e oikía. Sendo assim, poderia muito bem ter empregado o vocábulo oîkos em Lc 2,49c para referir-se ao Templo de Jerusalém. Por que, então, não o fez? Por que a imprecisão do trecho? É intencional? Com que propósito Lucas fez isso?

\subsection{Sentido funcional (coisas/assuntos/negócios)}

De Jonge argumenta que a construção tá toû seguida de genitivo de um substantivo, indicando uma pessoa com o sentido "casa de", nunca ocorre em Lucas ou no Novo Testamento (DE JONGE, 1978, p. 332). Essa ideia seria extraordinária em Lucas, de acordo com alguns textos neotestamentários, que justificam a interpretação "coisas" (DE JONGE, 1978, p. 332)25. Também argumenta que, na literatura cristã primitiva, a expressão "as

\footnotetext{
${ }^{21}$ Lc 7,6.10; 7,36.37.44; 8,27.39; 8,41.51; 10,5a.b.7a; At 10,17.22; 10,30.32; 11,11.12.13.

${ }^{22}$ At 2,$46 ; 5,42 ; 8,3 ; 12,12 ; 20,20$.

${ }^{23}$ Cf. Lc 19,5.9; At 10,2.22.30; 11,12.13.14; 16,31.34.

${ }^{24}$ Lc 6,$4 ; 11,51 ; 13,35 ; 19,46$; At 7, 46.47.49.

${ }^{25}$ Mc 8,33; Mt 22,21; 1 Cor 2,11; 7,32.34; 13,11.
} 
coisas de meu Pai" (tōn tô̂ patrós mou) ocorre literalmente no lógion 61, do Evangelho de Tomé (DE JONGE, 1978, p. 332-333) ${ }^{26}$.

De Jonge não nega a possibilidade da interpretação "na casa", mas levanta a questão se realmente Lucas não quis com a expressão enigmática aproveitar sua ambivalência. Nesse caso, a interpretação "nas coisas" faz bastante sentido (DE JONGE, 1978, p. 333). Ele apresenta quatro razões para justificar uma interpretação ambivalente em detrimento de um significado exclusivista "na casa de meu Pai"27. E, no final, ele afirma o seguinte:

Parece justificado concluir que Lucas usou um modo de se expressar com dois significados. O primeiro, que apesar de sua formulação incomum se incute no leitor do texto grego, é: 'Eu devo estar na casa de meu Pai, i.é., o templo' [sic]. O segundo é: 'Eu devo ocupar-me com os negócios de meu Pai' (DE JONGE, 1978, p. 335, tradução nossa) ${ }^{28}$.

De Jonge propõe, pois, uma interpretação ambivalente para o en toîs, mas não nega a possibilidade de essa expressão significar "Eu devo estar na casa de meu Pai", dada sua atestação na Septuaginta, papiros, autores e Padres gregos que interpretam nesse sentido (DE JONGE, 1978, p. 331332). Outro fator seria a sequência lógica dada às palavras "por que me procurais...", que dá a entender que a busca dos pais era desnecessária, pois deviam saber onde Jesus estaria (DE JONGE, 1978, p. 332). Ele afirma ainda que, se Lucas quisesse dizer "na casa", ele o fez "de uma forma não natural e até de maneira extraordinária" (DE JONGE, 1978, p. 332, tradução nossa). O emprego do vocábulo ô̂kos seria o "natural", já que se encontra em várias passagens lucanas ${ }^{29}$.

Para De Jonge, em nenhuma língua essa ambivalência é suscetível de uma interpretação satisfatória. O tradutor é, pois, confrontado a escolher uma

\footnotetext{
${ }^{26}$ A Synopsis de K. Aland (1971, p. 564) apresenta a tradução "coisas" para o en tô̂s no logion 61, no latim (ex illis Patris mei), alemão (von den Sachen meines Vaters) e inglês (that which is my Father's).

${ }^{27} 1$. O uso do verbo dêิ diz respeito ao ministério de Jesus como um todo, e não apenas ao evento pascal (cf. Lc 4,43; 9,22; 22,37). Usando o item verbal dêे, Lucas quer dar a entender que a permanência de Jesus no Templo deve ser entendida como parte de sua tarefa na realização do plano de Deus; 2. A descida de Jesus a Nazaré torna incongruente a interpretação "eu devo estar na casa (Templo) de meu Pai"; 3. A incompreensão dos pais em relação à declaração de Jesus seria um sinal para os leitores de que o v. 49 possui um significado mais profundo do que o óbvio; 4. A questão "Não sabíeis...?" assume uma resposta positiva e esperava-se que os pais estivessem cientes disso. Mas, no contexto da narrativa, não se poderia esperar que eles soubessem que seu filho estaria na "casa de Deus" (DE JONGE, 1978, p. 333-334). ${ }^{28}$ Os negócios (ou as coisas) do Pai referem-se a tudo o que Deus realizou por meio de Jesus: a proclamação (Lc 4,43) e doação do reino de Deus (Lc 12,32), o cumprimento da promessa de seu Pai $(24,49)$ e a doação do Espírito Santo (At 2,33) etc. (DE JONGE, 1978, p. 335); a interpretação "negócios" é assumida pelas seguintes traduções: holandesa Statenvertaling (SVV) (1637); inglesa: King James Version (KJV) (1769) e alemã Lutherbibel (LUO) (1912), disponíveis no software BibleWorks 8; as duas versões portuguesas: João Ferreira de Almeida, Almeida Revista e Corrigida (ARC) (1969) e João Ferreira de Almeida, Almeida Corrigida Fiel (ACF) (1753/1819/1847/1994/1995), também disponíveis no software BibleWorks 8.

${ }^{29}$ Lc 16,27; 19,5; 6,4; 19,46; At 7,47; Lc 11,51.
} 
tradução. E seria inadequado e insuficiente escolher uma tradução e, depois, indicar em nota de rodapé as outras possibilidades (DE JONGE, 1978, p. 335). O melhor seria, então, chamar a atenção para o fato de que ambas as traduções correspondem à intenção do autor. E, na impossibilidade de uma nota, a tradução mais adequada para a compreensão do leitor seria: "devo me ocupar com as coisas de meu Pai" (DE JONGE, 1978, p. 335) ${ }^{30}$.

Segundo Schürmann, a própria pergunta de Jesus em resposta a sua mãe já soa ambígua, pois se refere à obviedade do fato. Em sua determinação já ressoa o item verbal deî da segunda parte da resposta. O dito é pronunciado no Templo como lugar da instrução, e não lugar do sacrifício e da oração. Por isso, a tradução "estar naquilo que é de meu Pai" retrata bem a total dedicação e exclusividade à Palavra de Deus, que é característico do comportamento de Jesus e de sua constante busca (SCHÜRMANN, 1983, p. 266) ${ }^{31}$.

Ferraro (1983, p. 176-177), em sua obra sobre os relatos da infância, adota a tradução "Não sabíeis que eu devo ocupar-me das coisas do meu Pai?", mas não justifica sua escolha. Seu comentário sobre o trecho centra-se na ideia da consciência que Jesus, aos doze anos, tinha de sua relação única com Deus (FERRARO, 1983, p.176-177). Segundo Ferraro (1983, p. 177), o dito de Jesus revela o caráter profético do seu gesto e eleva sua obediência a um nível além do humano.

Para Weinert (1983, p. 22-23), ambas as interpretações "na casa de meu Pai" e "nos assuntos de meu Pai" sofrem da mesma imperfeição, pois salientam apenas um dos três sentidos de Lc 2,49c - espacial, funcional e pessoal -, e também silenciam a força pessoal da declaração de Jesus. Segundo ele, o sentido deve ser encontrado não apenas pelo caminho analítico, mas na própria característica multifacetada dos dados contidos em Lc 2,41-50 e na temática da peregrinação, que é potencialmente unificadora no episódio (WEINERT, 1983, p. 21-22) 32. Assim, o autor sugere traduzir a expressão

\footnotetext{
${ }^{30}$ Algumas traduções da Bíblia assumem essa interpretação mais indefinida do en tô̂s: A versão greco-italiana do Novo Testamento Graece de NESTLE-ALAND (1996); uma versão italiana da TOB (1995); as versões latinas Vulgata e Nova Vulgata (“[...] quia in his, quae Patris mei sunt [...]"); algumas traduções brasileiras: Bíblia Mensagem de Deus (1994), Bíblia Sagrada Ave-Maria (2009), Nova Bíblia Pastoral (2014). As duas obras: GOMES, Paulo S.; OLIVETTI, Odayr (trad.). Novo Testamento Interlinear Analítico Grego-Português - Texto Majoritário com Aparato Crítico. São Paulo: Cultura Cristã, 2008 e LUZ, Waldyr C. Novo Testamento Interlinear. São Paulo: Hagnos, 2010, traduzem o en tô̂s tô̂ patrós mou por "em as [coisas] do Pai [...]". ${ }^{31}$ A Bíblia Sagrada, tradução oficial da CNBB (2019) e a Bíblia Sagrada de Aparecida (2009), optam pelo vocábulo "naquilo", semanticamente equivalente a "coisas" ou "negócios".

${ }^{32}$ Segundo o estudo sobre o motivo da peregrinação, o peregrino tem a possibilidade de alcançar, no final da peregrinação, uma transformação salvífica. Foi, segundo ele, o que aconteceu com Jesus ao demorar-se no Templo. Weinert conclui: “Em suma, dentro do seu presente contexto de peregrinação, Lucas pode usar o dito em 2,49 simultaneamente para afirmar o lugar único de Jesus no plano salvífico de Deus, o seu papel ativo, e o distintivo vínculo pessoal com Deus que isso implica" (1983, p. 22).
} 
en tô̂s tô̂u patrós mou por "na companhia de meu Pai"33. Essa tradução explora os múltiplos significados da palavra "company", que em inglês pode designar proximidade pessoal, grupo social ou aliança em uma sociedade mista e, também, preserva as dimensões espacial, pessoal e dinâmica de Jesus observadas em Lc 2,49 (WEINERT, 1983, p. 22).

Sylva (1987, p. 132-140) apresenta um estudo do significado da palavra tô̂s e da cláusula ambígua de Lc 2,49c. Ele afirma que os argumentos usados por De Jonge, que atribui à expressão um duplo sentido, são inconclusivos e precisam ser provados. Para isso, é necessário abordar duas questões para esclarecer o duplo sentido dado por Lucas: a que "assuntos" Lucas se refere e por que ele liga esses assuntos ao Templo por tal dito (SYLVA, 1987, p. 134). A tese de Sylva é que tô̂s em Lc 2,49c tem um duplo sentido e seu significado seria: "Não sabíeis que devo estar preocupado com as palavras de meu Pai no Templo?" Assim, o trecho refere-se à necessidade do ministério de ensino de Jesus no Templo de Jerusalém, pois o uso da forma verbal dêे, que Lucas emprega ao longo do Evangelho, refere-se a diferentes aspectos do ministério de Jesus (SYLVA, 1987, p. 134) (34 $^{\text {. }}$

Bovon adota a interpretação "junto a meu Pai" por apresentar um duplo sentido, local e funcional, e afirma que uma resposta enigmática se encaixa muito bem no gênero da anedota (1995, p. 232). Junto com o verbo dêे, o trecho anuncia algo além desta cena, a saber: o destino de Jesus, assumido por ele e querido por Deus. Para Bovon (1995, p. 232), a resposta enigmática de Jesus confere um valor simbólico a sua atitude; a permanência inesperada no Templo converte-se na parábola de toda a obra do Messias.

Para Valentini (1992, p. 268), a nível redacional, o v. 49 constitui o clímax do relato de Lc 2,41-52 e o ponto de chegada de toda a cristologia de Lc 1-2. Por isso, interpretar acertadamente o dito de Jesus se torna imprescindível para a compreensão profunda da cristologia presente não apenas neste trecho, mas em toda a narrativa da infância. Essa compreensão se torna ainda mais urgente na medida em que se volta para os caps. 1-2 como introdução teológica à obra lucana (VALENTINI, 1992, p. 261). Assim, o trabalho consiste em encontrar o vocábulo que melhor explique o sentido da palavra "tô̂s" na formulação enigmática da frase final do v. 49 (VALENTINI, 1992, p. 288).

\footnotetext{
${ }^{33}$ Essa ideia encontra-se na conhecida Bíblia Tradução Ecumênica - TEB (1994), que oferece a seguinte tradução: "Não sabíeis que eu devo estar junto do meu Pai?". Em nota de rodapé, a TEB afirma que a tradução "Que eu devia estar ocupado com os negócios de meu Pai" foi feita muitas vezes, mas seria menos conforme o emprego dos termos e não convinha à situação, pois Jesus ainda não tinha começado sua missão.

34 "Dei é usado em Lc 2,49 para expressar a necessidade de Jesus estar en tois tou patros [sic]. Contudo, Lucas usou dei para referir-se à necessidade de 1) sofrimento de Jesus (Lc $9,22 ; 17,25)$, 2) sofrimento de Jesus, morte e ressurreição (Lc 24,7), 3) sofrimento de Jesus e glorificação (Lc 24,26), 4) pregação de Jesus do Reino de Deus (Lc 4,43), 5) estadia de Jesus com Zaqueu (Lc 19,5), 6) o cumprimento da escritura que Jesus foi 'contado com os transgressores' (Lc 22,37)" (SYLVA, 1987, p. 134).
} 
Assim, Valentini (1992, p. 277) adota a tradução "não sabíeis que devo estar junto ao meu Pai?", mas não explica sua opção por essa tradução. Sua análise do trecho centraliza a atenção no tema da revelação da identidade filial do menino Jesus, evidenciado no contraste entre os sintagmas "teu pai e eu" e "meu Pai". Mais adiante, considera alguns pontos da narrativa, entre eles, o valor cristológico da expressão en tô̂s tôu patrós mou (VALENTINI, 1992, p. 278-290). Para Valentini (1992, p. 288), o dado verdadeiramente notável no episódio é a revelação explícita de Jesus como Filho de Deus, mas a forma elíptica de Lc 2,49c não exprime a que se refere a locução dê̂ eînaí, da qual depende a missão e a escolha de Jesus. E, portanto, pergunta-se que palavra seria subentendida por trás do artigo tô̂s que deixa o texto impreciso. Ele apresenta uma síntese das propostas de alguns autores, deixando claro o mérito de trazer à luz a complexidade e a polivalência da expressão, na qual o significado não pode ser univocamente determinado (VALENTINI, 1992, p. 289).

Contudo, alguns anos depois, em sua obra "Vangelo d'infanzia secondo Luca" (2017, p. 329), Valentini adota outra tradução para Lc 2,49c: "Não sabíeis que eu devo ocupar-me das coisas de meu Pai?". Ele não descarta a possibilidade da tradução "na casa", mas concorda com Bovon ao afirmar que o trecho poderia ter um duplo sentido que, segundo ele, seria "na casa" e "nos negócios", baseado no fato de que Lucas ama os duplos sentidos (VALENTINI, 2017, p. 346).

Muñoz Nieto (1994, p. 130), em sua abordagem estrutural de Lc 1,5-2,52, no que se refere ao episódio de Lc 2,41-52, dedica-se a mostrar a estrutura e sua relação interna. Ele adota uma tradução literal do trecho em questão, com a seguinte tradução do v. 49c: "não sabíeis que no de meu Pai devia estar eu? [isto é, naquilo que é de meu pai]" (MUÑOZ NIETO, 1994, p. 130, tradução nossa). Ele não se atém à discussão sobre o significado do en tô̂s, provavelmente por estar consciente de que o artigo definido plural neutro tô̂s contém o sentido de pronome indefinido. Todavia, ele concorda com De Jonge em que se deve manter a ambiguidade da expressão, deixando a indeterminação daquilo que se pode entender como "a casa de" ou "os assuntos de" (MUÑOZ NIETO, 1994, p. 136).

Coleridge concorda com a posição de De Jonge, de que a expressão enigmática não pode se restringir a uma única interpretação como "na casa de meu Pai", pois este seria apenas um dos vários significados que o narrador combina a ambiguidade da expressão ${ }^{35}$. Segundo Coleridge (2000, p. 208),

\footnotetext{
${ }^{35} \mathrm{O}$ autor fala de ambiguidade no sentido de que a frase dita por Jesus em Lc 2,49 oferece ao leitor mais de um significado. Embora este vocábulo tenha uma conotação obscura, negativa, a maioria dos autores aqui apresentados o emprega para falar da imprecisão da locução en tô̂s no dito, ou seja, que admite mais de uma leitura. Essa acepção encontra-se no português, segundo HOUAISS, Antonio et. al. (Dirs.). Dicionário Houaiss da Lingua Portuguesa. Rio de Janeiro: Objetiva, 2001, p. 183.
} 
uma tradução preferivelmente imprecisa como "nas coisas de meu Pai" reflete melhor a ambiguidade do termo. Essa ambiguidade teria a função de levar o leitor a partilhar da perplexidade dos pais e a perguntar-se o que poderia significar esse "estar nas coisas do meu Pai", interrogação essa que terá sua resposta ao longo da narrativa lucana (COLERIDGE, 2000, p. 209).

Aletti (2012, p. 67) afirma que se deve reconhecer no trecho uma técnica narrativa cujo objetivo consistiria em compartilhar com o leitor a dificuldade dos pais em compreender o que Jesus quer dizer. Embora ressalte que a frase permanece enigmática pela ausência de um substantivo, ele adota a interpretação "nos assuntos de meu Pai" (ALETTI, 2012, p. 68) ${ }^{36}$.

Segundo a função que a narrativa do reencontro de Jesus no Templo exerce no Evangelho lucano, explica-se o porquê da escolha de Aletti pela interpretação "assuntos". Para ele, o narrador prepara para o seu leitor, mediante a declaração em Lc 2,49, a parte central da narrativa, a saber, a práxis de Jesus. É, pois, mediante a práxis que o próprio Jesus desvelará sua identidade messiânica ao longo do seu ministério público (ALETTI, 2012, p. 69).

Se muitos autores renomados insistem em afirmar que o dito de Jesus em Lc 2,49c permanece enigmático devido à ausência de um substantivo, por que não pensar na intenção de Lucas em escrever a locução en toîs por seu caráter ambivalente? Não seria esse um procedimento retórico lucano, com a intenção de deixar o dito de Jesus ambíguo, ou melhor, ambivalente?

\section{A ambivalência da expressão en tô̂s no dito de Jesus}

Segundo alguns autores atuais, a ambivalência do dito de Jesus no relato de Lc 2,41-52 seria proposital (COLERIDGE, 2000, p. 209; ALETTI, 2012, p. 68; VALENTINI, 2017, p. 346). A utilização de termos ou temas de duplo sentido deve ser considerado, segundo o estudo de Marguerat (2003, p. 73-90), um procedimento retórico de Lucas, cuja função é fazer-se compreender por seus leitores de cultura judaica e helenista ${ }^{37}$. A utilização deliberada de Lucas desse procedimento de ambivalência semântica é atestada em alguns textos de Lucas-Atos ${ }^{38}$.

\footnotetext{
${ }^{36} \mathrm{O}$ autor coloca a questão se, de fato, a resposta de Jesus a Maria indica o "Templo" ou o "ocupar-se dos assuntos de Deus". A ambiguidade da indicação convida a examinar mais de perto o conjunto da frase.

${ }^{37}$ Segundo Marguerat, a intenção de Lucas é situar a escrita entre duas realidades culturais: Israel e o Império Romano. E, para isso, Lucas "não elabora simplesmente uma accommodation da tradição judeu-cristã a um público greco-romano, ele desenvolve antes entre Jerusalém e Roma o que chamo de "um programa teológico de integração'" (MARGUERAT, 2003, p.74). ${ }^{38}$ Marguerat (2003, p. 74-76) também apresenta a composição de personagens "ambíguos" como exemplificação desse procedimento retórico: Paulo, Barnabé, Timóteo etc.
} 
No relato da Paixão (Lc 23), Lucas modifica sua fonte (Mc 15) quanto à declaração do centurião sobre Jesus na cruz. Em Mc 15,39, o centurião afirma: Alēthồs hoûtos ho ánthrōpos huiòs theoû $\hat{e} n$ (Verdadeiramente, este homem era filho de Deus); e em Lc 23,47: Óntōs ho ánthrōpos hoûtos díkaios $\hat{\bar{e}} n$ (Certamente, este homem era justo). O vocábulo díkaios admite dois sentidos, do ponto de vista lexicográfico: o sentido jurídico de inocência e o teológico do justo sofredor (MARGUERAT, 2003, p. 77). De acordo com essas observações, Marguerat questiona se Lucas não pretendeu essa ambiguidade, com a intenção de inscrever a morte de Jesus "na linha helenista do mártir inocente e na tradição judaica do servo sofredor" (MARGUERAT, 2003, p. 77) ${ }^{39}$. Dessa forma, a morte de Jesus pode ser entendida pelos leitores grego e judeu. A sequência, marcada por declarações de inocência (Lc 23,4.14.22 [Pilatos]; 23,41 [malfeitor]) confirma o caráter consciente dessa ambiguidade ${ }^{40}$.

Segundo Marguerat, a repetida ocorrência em Lucas-Atos dessa ambivalência semântica talvez não indique falta de clareza de Lucas, mas o emprego deliberado da figura literária denominada anfibologia ${ }^{41}$. "Lançar mão da anfibologia é o cálculo deliberado de um autor decidido a sugerir o duplo significado de uma palavra ou de um acontecimento, ela interpela e intriga. Ela propõe. Ela surpreende por deixar de limitar o sentido" (MARGUERAT, 2003, p. 82).

\section{A ambivalência do sintagma en toîs toû patrós mou como estratégia comunicativa}

Considerando, pois, que a ambivalência semântica em Lucas-Atos é um procedimento linguístico lucano, é plausível afirmar a ambivalência proposital do dito de Jesus em Lc 2,49c. Essa ambivalência não exclui o sentido local, mas pelo contrário, inclui o Templo entre as "coisas" de que Jesus deve ocupar-se. Bem como afirmou De Jonge, o tradutor do texto deve confrontar-se com a escolha da tradução para a locução en toîs. Por esse motivo, propomos a seguinte tradução para Lc 2,49c: "Não sabíeis que devo estar naquilo que é de meu Pai?", pois conserva a ambivalência do termo e instiga o leitor a descobrir ao longo da narrativa evangélica o significado enigmático da resposta de Jesus.

\footnotetext{
${ }^{39}$ Marguerat (2003, p. 77) emprega o vocábulo ambiguidade como sinônimo de ambivalência ao referir-se à dualidade de sentido dos vocábulos usados por Lucas em sua narrativa. ${ }^{40}$ Essa ambivalência lucana também é exemplificada em outros textos: Discurso de Paulo em Atenas (At 17,16-34); At 27-28 (MARGUERAT, 2003, p. 78-80).

41 "A anfibologia é uma figura retórica empregada corriqueiramente pelos estudiosos dos midrashim. No tratado bMegila $14 \mathrm{~b}$ dá-se o nome de tartey machma ao uso voluntário do duplo sentido" (DUMAIS, 1976, p. 94 apud MARGUERAT, 2003, p. 82).
} 
Retomando, pois, a ideia de Coleridge, de que a imprecisão do dito de Jesus visa dividir com o leitor a perplexidade dos pais em relação à atitude de Jesus no Templo e perguntar-se pelo significado do "estar naquilo que é de meu Pai", reafirmamos a intencionalidade de Lucas, que cria no leitor o desejo de buscar pela resposta em seu itinerário de leitura do Evangelho. Para Aletti (2012, p. 69), Lucas prepara para seu leitor, mediante a declaração misteriosa de Lc 2,49 c, a parte central da narrativa, em que será desenvolvida a práxis de Jesus, como reveladora de sua identidade messiânica.

Pois bem, essa ambivalência denota o ambiente judeu-helenista no qual Lucas está inserido. Afirmamos que faz parte da estratégia comunicativa de Lucas concluir o relato da infância com um episódio centrado nas primeiras palavras de Jesus, que desvela sua identidade e missão com uma declaração ambivalente. Essa ambivalência deixa o final da narração da infância aberto, pois constitui uma afirmação relativa à identidade messiânico-filial de Jesus que aponta, prolepticamente, para sua atuação pública (Lc 3-24). Tal declaração, para ser bem compreendida, deve ser analisada no contexto comunicativo em que é proferida, o episódio de Jesus aos doze anos (Lc 2,41-52), levando em consideração todo o percurso de leitura, desde o prólogo (Lc 1,1-4) ao relato da apresentação de Jesus no Templo (Lc 2,21-40). Nesse processo, Lc 2,41-52 conclui a progressiva revelação da identidade de Jesus - Messias e Filho de Deus - no relato da infância (Lc 1-2), que aponta para a revelação de Jesus - Messias, Profeta e Filho de Deus - na narrativa evangélica (Lc 3-24), cujo dever fundamental consiste em estar naquilo que é de seu Pai e em cumprir a obra salvífica de Deus em prol da humanidade, em outras palavras, "procurar e salvar o que estava perdido" (Lc 19,10).

\section{Conclusão}

A exposição das diversas opiniões a respeito da interpretação da cláusula enigmática en toîs tôu patrós mou incide sobre a dificuldade de encontrar um substantivo que melhor traduza os termos en toîs.

Os autores que optaram pela interpretação "na casa de meu Pai" levam em consideração as indicações locais que perpassam a narração e o lugar onde Jesus foi encontrado, o Templo de Jerusalém. Além disso, as bases escriturísticas e as referências aos autores da patrística e da modernidade são bem amplas. No entanto, segundo as opiniões dos diversos autores estudados, não se pode negar a dificuldade de uma interpretação unilateral dos termos en toîs para uma compreensão mais ampla da mensagem veiculada pelo dito de Lc 2,49. 
Dessa mentalidade é que se abre a perspectiva de uma interpretação mais "aberta" do referido dito, aproveitando a ambivalência dos termos en tô̂s que, gramaticalmente falando, nada mais é do que um corriqueiro neutro com valor de pronome indefinido. Os expositores da interpretação funcional não descartam a referência ao lugar, mas reiteram que ambos os sentidos são possíveis. Nesse caso, a melhor opção que retrata essa ambivalência seria o vocábulo "naquilo", por conservar essa imprecisão, além de corresponder gramaticalmente à tradução literal do plural neutro indefinido (en tô̂s) e semanticamente equivalente a "coisas" ou "negócios".

A análise do emprego das palavras oîkos e oikía na obra lucana revela que o evangelista conhecia bem esses vocábulos, inclusive a palavra oîkos como metáfora da casa do Pai (Templo). Todavia, todas as ocorrências em LucasAtos do item lexical ô̂kos em analogia ao Templo não são matéria original de Lucas, mas de suas fontes. O conhecimento lucano do vocábulo ốkos levanta a questão do porquê ele não o utilizou no dito de Jesus em Lc 2,49 c, e se isso seria proposital ou não. A isso, soma-se a ideia de alguns autores aqui estudados sobre a hipótese de Lucas ter empregado propositalmente os termos en tô̂s com a finalidade de manter a ambivalência do dito de Jesus em Lc 2,49.

Uma breve abordagem acerca de alguns textos lucanos, que testificam a ambivalência semântica como procedimento retórico, fundamenta a hipótese do emprego proposital da locução en tô̂s no dito de Jesus (Lc 2,49c). Assim, é justificável que a melhor interpretação para essa locução seja uma que conserve a ambivalência de sentidos, o que instigaria o leitor a descobrir no decorrer da narrativa evangélica o significado da resposta de Jesus.

Dessa maneira, a ambivalência do pronunciamento de Jesus no Templo (Lc 2,49c), no final da narrativa da infância (Lc 2,41-52), constitui estratégia do autor que conclui sua revelação cristológica com um final aberto a ser preenchido pelo leitor, mediante o processo de desvelamento da identidade messiânica de Jesus que continuará ao longo do Evangelho.

\section{Referências}

ALAND, K. Synopsis quattor evangeliorum: locis parallelis evangeliorum apocryphorum et patrum adhibitis edidit. 7.Aufl. Stuttgart: Wurttembergische Bibelanstalt, 1971.

ALETTI, J-N. Il Gesù di Luca. Bologna: Dehoniane, 2012.

Ambiguidade. HOUAISS, Antonio et. al. (Dirs.). Dicionário Houaiss da Lingua Portuguesa. Rio de Janeiro: Objetiva, 2001, p. 183. 
BIBBIA. Traduction Oecuménique. Edizione integrale. Leumann, Torino: Editrice Elle Di Ci, 1995.

BÍBLIA de Jerusalém. Nova ed. rev. e ampl. São Paulo: Paulus, 2002.

BÍBLIA do Peregrino. 3.ed. São Paulo: Paulus, 2011.

BIBLIA Sacra Iuxta Vulgatam Versionem. 5.ed. São Paulo: Sociedade Bíblica do Brasil, 2006.

BÍBLIA Sagrada Almeida século 21: Antigo e Novo Testamento. Coordenação das revisões exegéticas e de estilo da versão Bíblia Almeida Século 21 por Luiz Alberto Teixeira Sayão. São Paulo: Vida Nova, 2008.

BÍBLIA Sagrada Ave-Maria. Ed. rev. São Paulo: Claretiana, 2009.

BÍBLIA Sagrada de Aparecida. Aparecida: Santuário, 2009.

BÍBLIA Sagrada. Traduzida em português por João Ferreira de Almeida. Ed. ver. e atual. no Brasil. São Paulo: Sociedade Bíblica do Brasil, 1993.

BÍBLIA Sagrada: nova tradução na linguagem de hoje. São Paulo: Sociedade Bíblica do Brasil, 1989.

BÍBLIA Sagrada: nova versão internacional. São Paulo: Sociedade Bíblica Internacional, 2000.

BÍBLIA Sagrada: tradução oficial da CNBB. 2.ed. Brasília: CNBB, 2019.

BÍBLIA. Novo Testamento Interlinear Grego-Português. Barueri, SP: Sociedade Bíblica do Brasil, 2004.

BÍBLIA. Tradução Ecumênica. São Paulo: Loyola, 1994.

BÍBLIA: mensagem de Deus. São Paulo: LEB; Loyola, 1994.

BÍBLIA: nova edição pastoral. São Paulo: Paulus, 2014.

BIBLIA: Nova vulgata Bibliorum Sacrorum editio. Sacros. Oecum., Concilii Vaticani II ratione habita; iussu Pauli PP. VI recognita; auctoritate Ioannis Paulis PP. II promulgata. Editio typica altera. 2.ed. Città del Vaticano: Libreria Editrice Vaticana, 1986.

BIBLEWORKS. BibleWorks 8: Versão 8.0.013z.1. Norfolk: Bibleworks, LLC, 2009. CDROM.

BOVON, F. El evangelio según San Lucas I: Lc 1-9. Salamanca: Sigueme, 1995. (BEB, 85).

BROWN, R. E. The Birth of the Messiah: a commentary on the infancy narratives in Matthew and Luke: new updated edition. New York: Doubleday, 1993.

COENEN, L.; BROWN, C. (Orgs.). Dicionário Internacional de Teologia do Novo Testamento. São Paulo: Vida Nova, 2000. p. 285-289.

COLERIDGE, M. Nueva Lectura de la Infancia de Jesús: la narrativa como cristología en Lucas 1 - 2. Madrid: Almendro Córdora, 2000. 
DE JONGE, H. J. Sonship, wisdom, infancy: Luke ii. 41-51a. New Testament Studies, v. 24, n. 3, p. 317-354, Apr. 1978.

FERRARO, G. I Racconti dell'Infanzia nel Vangelo di Luca. Napoli: Dehoniane, 1983.

FITZMYER, J. A. El Evangelio según Lucas: Tomo II: traduccion y comentário capítulos 1-8,21. Madrid: Cristianidad, 1987.

GOMES, P. S. OLIVETTI, O. (trad.). Novo Testamento Interlinear Analítico Grego-Português - Texto Majoritário com Aparato Crítico. São Paulo: Cultura Cristã, 2008.

KONINGS, J. A Bíblia, sua Origem e sua Leitura. 8.ed. Petrópolis: Vozes, 2014.

LAURENTIN, R. Jésus au Temple: mystère de paques et foi de Marie em Lc 2,4850. Paris: Lecoffre, 1966.

LOUW, J.; NIDA, E. (Eds.). Léxico Grego-Português do Novo Testamento Baseado em Domínios Semânticos. Barueri: Sociedade Bíblica do Brasil, 2013. p. 74, 103, 105, 119, 499.

LUZ, Waldyr C. Novo Testamento Interlinear. São Paulo: Hagnos, 2010

MARGUERAT, D. A Primeira História do Cristianismo: Atos dos Apóstolos. São Paulo: Loyola, 2003.

MORGENTHALER, R. Statistik des Neutestamentlichen Wortschatzes. 4.Aufl. Zürich: Gotthelf-Verlag, 1992.

MOUNCE, W. D. (Ed.). Léxico Analítico do Novo Testamento Grego. São Paulo: Vida Nova, 2013, p. 424, 437-438.

MUÑOZ NIETO, J. M. Tiempo de Anuncio: estudio de Lc 1,5-2,52. Taipei: Facultas Theologica S. Roberto Bellarmino, 1994.

NESTLE-ALAND. Nuovo Testamento Greco-Italiano. A cura di Bruno CORSANI e Carlo BUZZETTI. Roma: Società Biblica Britannica \& Forestiera, 1996.

NESTLE-ALAND. Novum Testamento Graece. 2.Aufl. Stuttgart: Deutsche Bibelgesellschaft, 2012.

RODRÍGUEZ CARMONA, A. Jesús comienza su vida de adulto (Lc 2,41-52). Estudios Biblicos, Madrid, v. 50, n. 1-4, p. 177-189, 2ª época 1992.

RUSCONI, C. (Ed.). Dicionário do Grego do Novo Testamento. São Paulo: Paulus, 2003. p. 328-329.

SCHÜRMANN, H. Commentario Teologico del Nuovo Testamento: il vangelo di Luca. Brescia: Paideia, 1983. v. 3.

SWETNAM, J. Gramática do Grego do Novo Testamento. São Paulo: Paulus, 2004.

SYLVA, D. D. The cryptic "en tois tou patros mou dei einai me" in Lk 2:49b. Zeitschrift für die Neutestamentliche Wissenschaft und die Kunde der älteren Kirche, Berlin, v. 78, p. 132-140, 1987.

VALENTINI, A. La rivelazione di Gesù dodicenne al tempio (Lc 2,41-52). Estudios Bíblicos, Madrid, v. 50, n. 1-4, p. 261-304, 2ª época, 1992. 
VALENTINI, A. Vangelo d'Infanzia secondo Luca: riletture pasquali delle origini di Gesù. Bologna: Dehoniane, 2017.

WEIGANDT, P. Oĩkos, ov ó (oikos). BALZ, H.; SCHNEIDER, G. (Eds.). Diccionario Exegético del Nuevo Testamento. v. 2. Salamanca: Sigueme, 1998. p. 500-508.

WEINERT, F. D. The multiple meanings of Luke 2,49 and their significance. Biblical Theology Bulletin, Roma/New York, v. 13, n. 1, p. 19-22, Feb. 1983.

Artigo submetido em 18.12.2019 e aprovado em 23.06.2020.

Márcia Eloi Rodrigues é Doutora em Teologia Sistemática pela Faculdade Jesuíta de Filosofia e Teologia (FAJE), professora de Sagrada Escritura no Seminário Provincial Sagrado Coração de Jesus, em Diamantina e pesquisadora no Grupo de Pesquisa A bíblia em leitura cristã (FAJE). Orcid.org/0000-0002-9035-7948. E-mail: ir.marcianj@gmail.com

Endereço: Rua Atlético Mineiro, 650

Bairro Vila Esportiva

33202-374 Vespasiano - MG 